The patient's family requests continued futile therapy Guilt usually plays a part in the family's request to continue treatment, although religious and cultural factors may also contribute. Agreement can usually be obtained by explaining the rationale again and offering a second opinion from within or outside the intensive care team. It is best not to withdraw treatment if there is conflict. However, the final decision rests with the intensive care team. This underlines the need for good communication.

\section{The family requests inappropriate discontinuation of therapy}

The rationale behind the therapy and the reasons why continuing treatment is thought appropriate should be explained. The duty of care is to the patient, not the family. Again, a second opinion can be offered.

\section{The patient requests discontinuation of therapy.}

Explain to the patient the rationale for the treatment and that, in the opinion of the intensive care team, a chance of recovery exists. It may be appropriate to offer a short term contract for treatment (for example, 48 hours then review). Ultimately, the competent patient has the right to refuse treatment even if that treatment is life saving.

The living will was provided by Terence Higgins Trust and King's College London.

BMJ 1999;319:306-8
A 65 year old man is admitted to intensive care after a laparotomy for faecal peritonitis secondary to a perforated diverticulum. He needs mechanical ventilation, haemofiltration, and noradrenaline. Two days later his children (the next of kin) request discontinuation of treatment as they feel that their father would not wish to be put through this suffering and had strongly expressed such views. However, he shows evidence of clinical improvement and his requirements for noradrenaline and oxygen are significantly reduced. The intensive care team therefore felt that treatment should not be withdrawn. The man recovered and was discharged from hospital. It was later discovered that his family had apportioned his possessions while he was in intensive care

Bob Winter is consultant in intensive care, University Hospital, Nottingham, and Simon Cohen is senior lecturer in intensive care, University College London Hospitals, London.

The ABC of intensive care is edited by Mervyn Singer, reader in intensive care medicine, Bloomsbury Institute of Intensive Care Medicine, University College London and Ian Grant, director of intensive care, Western Infirmary, Edinburgh. The series was conceived and planned by the Intensive Care Society's council and research committee.

When I use a word ...

\title{
Allergy and immunity
}

At a witness seminar, 15 or so key figures are gathered together and allowed to talk freely about historical events in which they took part, supporting or correcting one another as may be. Tilly Tansey has organised more than a dozen of these at the Wellcome Institute for the History of Medicine since 1993, and two volumes of proceedings have been published by the Wellcome Trust (see Med Hist 1998; 42:404-5). In one of these meetings, "Self and Non-Self: a History of Autoimmunity," held in February 1995, Professor Robin Coombs from Cambridge complained about the word "autoimmunity," which he described as "misconstrued, absurd, and extremely confusing." The word we should use, he said, is "autoallergy."

The term allergy was invented by Von Pirquet (Münch Med Wochenschr 1906;30:1457), who intended it to mean altered reactivity, from the Greek $\lambda \lambda \circ \varsigma$ (allos), other and $\rho \gamma \varepsilon ı v$ (ergein), to work. He did not use the word to mean immunity or even hypersensitivity. Rather he meant that allergy was a response that could lead either to protective immunity on the one hand or damaging hypersensitivity on the other. And he made it quite clear that the term "immunity" should be restricted to cases in which the allergic response caused no clinically evident reaction. It follows that you cannot be immune to yourself nor suffer as a result.

But words change their meaning with time, and by metonymy (the identification of a thing with something associated with it), allergy came to mean hypersensitivity. And the concept of autoimmunity arose because in the 1950 s immunologists were trying to make animals generate antibodies to their own proteins. Goats, for example, were made to produce antibodies to their own lactoglobulin; and when rabbits were "immunised" against their own thyroglobulin and the response was accompanied by infiltration of inflammatory cells into the thyroid gland, the idea of autoimmune disease was born. But the animals that were so injected were not protected against their own proteins, they were sensitised to them; and it was the allergic response that caused the susceptibility to the disease.

Despite the efforts of Gell and Coombs in their famous textbook Clinical Aspects of Immunology (Blackwell, 1963, pp 317-20 and 805-7) to correct this misuse, it has persisted. I sympathise with Coombs's views on this, but it is really too late; we are stuck with autoimmunity, just as we are stuck with another immunological misuse, vaccination. Originally vaccination was immunisation against smallpox by the use of cowpox virus (Latin vacca, a cow). However, Louis Pasteur used the word to refer to other forms of immunisation, and the use has stuck. But perhaps we would be better to say inoculation.

Although the use may be regrettable, I don't think that calling autoallergic diseases "autoimmune" affects our ideas about them. I confess, however, that I would welcome it if those who proclaim themselves to be allergic to the twentieth century would instead believe themselves to be immune to it.

Jeff Aronson, clinical pharmacologist, Oxford

We welcome articles of up to 600 words on topics such as A memorable patient, A paper that changed my practice, My most unfortunate mistake, or any other piece conveying instruction, pathos, or humour. If possible the article should be supplied on a disk. Permission is needed from the patient or a relative if an identifiable patient is referred to. We also welcome contributions for "Endpieces," consisting of quotations of up to 80 words (but most are considerably shorter) from any source, ancient or modern, which have appealed to the reader. 